\title{
AN INTEGRATED APPROACH TO GREEN CONCEPT
}

\section{SELECTION}

\author{
Zeki Ayağ
}

Kadir Has University

\begin{abstract}
In the 21st Century, the consumer demand for environmental-friendly green products has dramatically increased due to the fact that the importance and public awareness of the preservation of natural environment. Based on this development, companies have been forced to design and manufacture more green products, resulting in a problem of how they incorporate environmental issues into their design (products), and evaluate concept options to determine ultimate one(s). Solving this problem needs a practical decision making tool, because the problem turns into a multiple-criteria decision making (MCDM) problem in the presence of a set of alternatives and evaluation criteria. That's why, in this paper, a fuzzy based AHP-PROMETHEE II, both of the most commonly used MCDM methods successfully applied for various problems, is used to reflect the vagueness and uncertainty on the judgments of a DM(s), because the crisp pairwise comparison in both conventional methods seems to be insufficient and imprecise to capture the right judgments of a DM(s). As fuzzy AHP is used to calculate the weights of evaluation criteria, the fuzzy PROMETHEE II is used to rank alternatives. In addition, to show the applicability of the proposed approach for potential practioners, a case study realized in a Canadian company is presented.
\end{abstract}

Keywords: AHP; fuzzy logic; green concept evaluation; multiple-criteria decision making; PROMETHEE II 